Review

\title{
Food-derived Acetylcholinesterase Inhibitors as Potential Agents against Alzheimer's Disease
}

\author{
Rotimi E. Aluko ${ }^{1,2, *}$ \\ ${ }^{1}$ Department of Food and Human Nutritional Sciences, University of Manitoba, Winnipeg, Manitoba, Canada R3T 2N2 \\ ${ }^{2}$ Richardson Centre for Functional Foods and Nutraceuticals, University of Manitoba, Winnipeg, Manitoba, Canada R3T 2N2
}

\section{ARTICLE INFO}

\section{Article History}

Received 20 February 2021 Accepted 17 March 2021

\section{Keywords}

Acetylcholinesterase

brain

neurotransmission

acetylcholine

polyphenols

bioactive peptides

Alzheimer's disease

\begin{abstract}
Acetylcholinesterase (AChE) is a critical enzyme involved in nerve functions and signal transmission within the brain. However, during aging, excessive AChE activity often leads to rapid and progressive depletion of acetylcholine (ACh), the major neurotransmitter. Shortage of ACh leads to reduced neurotransmission and the development of pathological conditions such as dementia and Alzheimer's Disease (AD). Therefore, one of the proven approaches toward the clinical management of $\mathrm{AD}$ is the use of compounds that inhibit AChE activity to produce enhanced brain levels of $\mathrm{ACh}$ and restore regular nerve functions in the brain. Hence the aim of this review is to provide information on recent advances in the use of various food-derived extracts and compounds as AChE-inhibitory agents. The major forms of AChE-inhibitory products are the aqueous or organic solvent extracts of various foods with polyphenolic compounds being the predominant constituents. Other types of food-derived AChE inhibitors include proteins, peptides, terpenoids and carotenoids. In addition to the proven efficacy at the in vitro level, several of these food products have been shown to be effective in reducing brain levels of AChE with concomitant improvements in memory functions. However, future research activities are needed to provide information on the structure-function and toxicological aspects of food-derived AChE-inhibitory compounds.
\end{abstract}

\section{GRAPHICAL ABSTRACT}

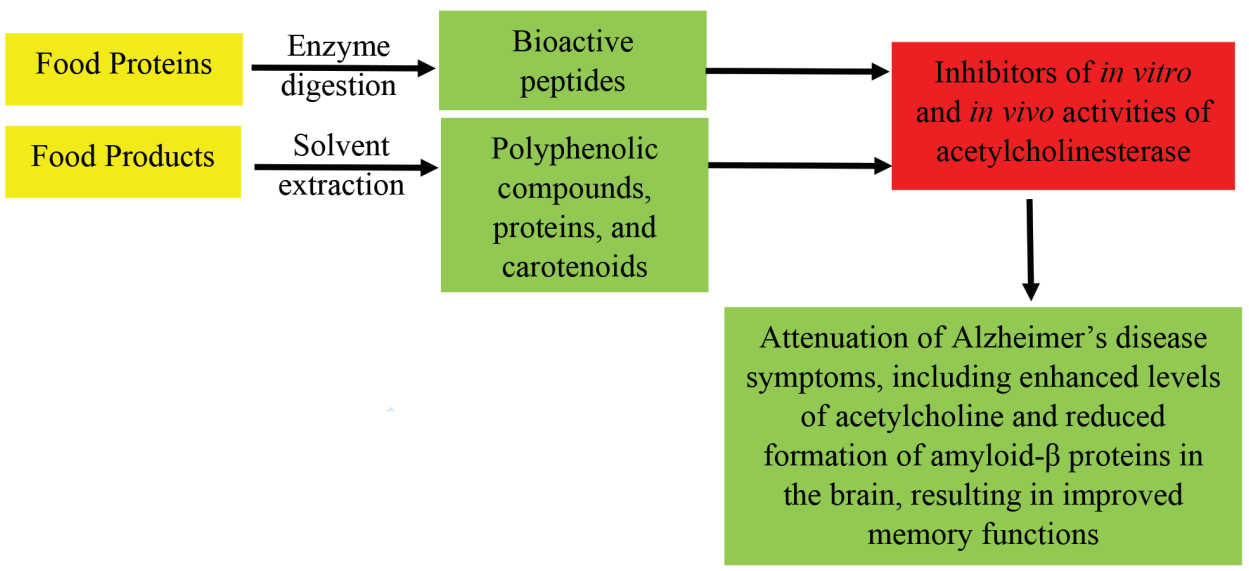

(C) 2021 The Author. Publishing services by Atlantis Press International B.V. This is an open access article distributed under the CC BY-NC 4.0 license (http://creativecommons.org/licenses/by-nc/4.0/).

\section{INTRODUCTION}

Alzheimer's Disease (AD) is a chronic neurodegenerative disorder that is responsible for most cases of cognitive and memory deterioration in the elderly population $[1,2]$. While the etiology and pathogenesis of this complex disease are yet to be fully unravelled, evidence suggests the important role of the Acetylcholine

"Email: rotimi.aluko@umanitoba.ca

Peer review under responsibility of the International Association of Dietetic Nutrition and Safety
(ACh) homeostasis in the prevention and treatment of AD symptoms $[1,2]$. This is because ACh is an integral part of neurotransmission, especially in the brain and its deficiency creates short circuits within the system whereby chemical signals cannot be properly relayed from nerves to the specific receptors within the brain. Under normal physiological conditions, $\mathrm{ACh}$ is released from the nerve into the synaptic cleft where it binds to receptors on the post-synaptic membrane to transmit nerve signals to the brain $[3,4]$. To prevent overstimulation of the brain, ACh is hydrolyzed by Acetylcholinesterase (AChE, EC.3.1.1.7) into choline and acetate, which are then recombined in the pre-synaptic nerve to 
regenerate $\mathrm{ACh}$. This important role of $\mathrm{AChE}$ ensures that the brain is not subjected to excessive nerve stimulation but also serves as a mechanism to recycle the two critical substrates required for ACh synthesis. Therefore, homeostatic levels of AChE are critical for normal maintenance of brain functions. However, during aging, reductions in choline level coupled with non-regeneration of used neurons lead to shortage of ACh. Since the level of AChE activity remains unchanged, the result is that the few ACh molecules available for nerve functions are continuously hydrolyzed, which leads to reduced signal transmission capacity. Continuous depletion of ACh levels leads to impaired functioning of nerve impulses coupled with inadequate signal transmission to the brain, which lead to attenuated brain functions, especially memory impairment such as in $\mathrm{AD}$ and dementia. Excessive levels of AChE activity have also been associated with the pathogenesis of $\mathrm{AD}$ through promotion of $\beta$-amyloid fibrils formation [5]. Thus, inhibition of AChE activity could reduce $\mathrm{ACh}$ hydrolysis, boost nerve functions and prevent chronic deterioration of brain functions, especially in relation to the pathogenesis of $\mathrm{AD}$ and dementia. Over the past several years, $\mathrm{AD}$ management has focused on the use of pharmacological agents to inhibit AChE activity and enhance ACh availability in the brain. Typical AChE-inhibitory drugs that have been approved for the treatment of $\mathrm{AD}$ patients include rivastigime, galanthamine and donezepil [1]. However, clinical usage of these drugs have been associated with several undesirable side effects such as decreased heart rate (bradycardia), decreased appetite and weight, increased gastric acid production, nausea, vomiting, and muscle cramps [6-9]. Therefore, recent research activities have investigated the potential use of natural compounds, especially those derived from various food sources as AChE inhibitors. This is because foodderived compounds may be better metabolized and tolerated by the human system, which could reduce or eliminate the negative side effects associated with drugs. One of the major challenges for food-derived compounds is their ability to cross the Blood-Brain Barrier (BBB), which could limit their therapeutic efficiency. This is because it is widely recognized that entry of molecules from blood circulation into the brain is strictly controlled by the BBB as a means of maintaining normal neuronal functions and information processing [10]. However, during aging and especially as memory impairment sets in for $\mathrm{AD}$ patients, there is a breakdown of the $\mathrm{BBB}$, which could enhance uptake of therapeutic products that would otherwise be prevented from crossing into the brain [10]. Thus, under the pathological environment associated with $\mathrm{AD}$, it is conceivable that entry of potent AChE inhibitors into the brain will be facilitated, which justifies the continued search for bioactive food-derived compounds. In this review, the structural and functional properties of food-derived AChE inhibitors are described to provide scientific information that could promote the use of these compounds as therapeutic agents against the onset and development of AD. As evident in Tables 1 and 2, there is already a diverse range of sources and reported activities of food-derived inhibitors, which will be discussed in the following sections.

\section{FOOD PROTEIN HYDROLYSATES AND FREE AMINO ACIDS}

Food protein hydrolysates are recognized as veritable sources of bioactive peptides that could have positive influence on human health without the undesirable negative side effects associated with drugs during long-term use $[11,12]$. The hydrolysates are usually obtained through enzymatic digestion of food proteins followed by separation of the peptides from undigested proteins. The relevance of food protein-derived peptides to $\mathrm{AD}$ management remains to be proven because of the paucity of scientific evidence showing peptide uptake from blood circulation into the brain. While very few reports have demonstrated the uptake of peptides into the brain, the presence of active peptide transporters (PT1-PT5) in the $\mathrm{BBB}$ indicates a physiological mechanism through which proteins and peptides could be transferred from blood circulation into the brain [13]. Moreover, the structural defects associated with the $\mathrm{BBB}$ during $\mathrm{AD}$ could enhance passive diffusion of peptides into the brain. One of the first works to examine the potential use of food-derived peptides as AChE inhibitors involved the purification of a peptide (31 amino acid residues) from Ziziphus jujuba fruits [14]. The peptide, which was named Snakin-Z showed effective in vitro inhibition of $\mathrm{AChE}$ activity with inhibitor concentration that reduced enzyme activity by $50 \%\left(\mathrm{IC}_{50}\right)$ value of $0.58 \mathrm{mg} / \mathrm{mL}$, which compares well with the $0.17 \mathrm{mg} / \mathrm{mL}$ for galanthamine (drug). Structural analysis of Snakin-Z revealed an abundance of hydrophobic amino acids, especially leucine, valine, tyrosine, alanine, proline, and glycine. Based on the bi-lipid membrane structure of cells, the presence of several hydrophobic residues could be considered an advantage in facilitating entry of Snakin- $Z$ into brain cells. Other authors have reported the AChE-inhibitory activity of hydrolysates produced from the enzymatic hydrolysis of hemp seed, anchovy and yeast proteins.

In a comprehensive report, Malomo and Aluko [3] reported the in vitro AChE-inhibitory activity of various hemp seed protein hydrolysates produced with different enzymes and at varying Degree of Hydrolysis (DH). The highest AChE inhibition (53.78\%) was obtained when the hemp seed was digested with $1 \%$ pepsin whereas digests from $2 \%$ to $4 \%$ pepsin were inactive. The hemp seed protein digest from $4 \%$ alcalase also showed strong AChE inhibition at $41.82 \%$, which was not different from the $39.51 \%$ for $3 \%$ papain digest [3]. However, there was no observed effect of $\mathrm{DH}$ on the AChE-inhibitory activity of the protein hydrolysates, which indicate that the peptide structure (amino acid composition and sequence) was the determinant factor rather than peptide chain length. The flavourzyme digests had the weakest AChE inhibition, which may be due to the inactivation of active peptides by the exopeptidase activity of this enzyme. The $\mathrm{IC}_{50}$ values for the most active hemp seed protein hydrolysates were reported as follows: $1 \%$ pepsin $(5.95 \pm 0.10 \mu \mathrm{g} / \mathrm{mL}), 3 \%$ pepsin $(8.04 \pm 0.33 \mu \mathrm{g} / \mathrm{mL}), 3 \%$ papain $(8.97 \pm 0.41 \mu \mathrm{g} / \mathrm{mL})$ and $4 \%$ alcalase $(11.62 \pm 0.32 \mu \mathrm{g} / \mathrm{mL})$. The results indicate stronger $\mathrm{AChE}$ inhibition by the hemp seed protein hydrolysates when compared to the Snakin- $Z$ peptide and galanthamine with $\mathrm{IC}_{50}$ values of 0.58 and $0.17 \mathrm{mg} / \mathrm{mL}$, respectively. In a subsequent report, the most active hemp seed protein hydrolysate (1\% pepsin) was separated by reverse-phase HPLC into seven fractions (F1-F7) with the F7 being the most active AChE inhibitor [15]. Kinetics analysis determined that the $1 \%$ pepsin hydrolysate and F7 inhibited human AChE through uncompetitive manner, which means that the peptides were bound mostly to the enzyme-substrate complex to reduce catalysis. The F7 fraction was a stronger AChE inhibitor with lower inhibition constant (stronger enzyme binding affinity) when compared to the protein hydrolysate, which indicates that separation of the peptides successfully enriched active peptides within this fraction. The F7 was also the most hydrophobic, which is consistent with the Snakin- $\mathrm{Z}$ amino acid composition that showed 
Table 1 Typical food sources of acetylcholinesterase (AChE) inhibitors and reported in vitro activities

\begin{tabular}{|c|c|c|c|c|}
\hline Sources & Extraction method & Active compound(s) & Inhibitory activity $\left(\mathrm{IC}_{50}\right)^{\mathrm{a}}$ & References \\
\hline Hemp seed protein & Enzyme hydrolysis & Peptides & $5.95 \mu \mathrm{g} / \mathrm{mL}$ & [3] \\
\hline Yeast & Citrate buffer & Mannoproteins & $7.70 \mathrm{mg} / \mathrm{mL}$ & [16] \\
\hline Ziziphus jujube & Water & Peptide & $0.58 \mathrm{mg} / \mathrm{mL}$ & {$[14]$} \\
\hline Tea & $80 \%$ Acetone & Cinnamoylated flavoalkaloids & $0.13 \mu \mathrm{M}$ & [22] \\
\hline Tea & Methanol & Hydroxycinnamoylated catechin & $2.49 \mu \mathrm{M}$ & [23] \\
\hline Safflower seed & Ethyl acetate & Carthatin A & $17.96 \mu \mathrm{M}$ & {$[25]$} \\
\hline Safflower seed & Ethyl acetate & Carthatin B & $66.83 \mu \mathrm{M}$ & [25] \\
\hline Hemp seed & Ethyl acetate & Polyphenols & $38.70 \mu \mathrm{g} / \mathrm{mL}$ & {$[28]$} \\
\hline Green gram & Ethanol & Polyphenols & $9.60 \mu \mathrm{g} / \mathrm{mL}$ & [29] \\
\hline Green gram & Water & Proteins $(12 \mathrm{kDa})$ & $6.82 \mu \mathrm{g} / \mathrm{mL}$ & [29] \\
\hline Mangosteen gram & Chloroform & Xanthonoids & $2.70 \mu \mathrm{g} / \mathrm{mL}$ & {$[31]$} \\
\hline Paper mulberry & Ethanol & Polyphenols & $12.10 \mu \mathrm{g} / \mathrm{mL}$ & {$[33]$} \\
\hline Myrciaria floribunda & Hydrodistillation & Sesquiterpenes & $0.08 \mu \mathrm{g} / \mathrm{mL}$ & {$[34]$} \\
\hline Grape skin & Methanol & Anthocyanins & $363.61 \mu \mathrm{g} / \mathrm{mL}$ & {$[35]$} \\
\hline Banana (field plant) & Methanol & Polyphenols & $4.22 \mu \mathrm{g} / \mathrm{mL}$ & {$[37]$} \\
\hline Banana (in vitro plant) & Methanol & Polyphenols & $81.85 \mu \mathrm{g} / \mathrm{mL}$ & {$[37]$} \\
\hline Banana (field plant) & Butanol & Polyphenols & $419.00 \mu \mathrm{g} / \mathrm{mL}$ & {$[37]$} \\
\hline Plum persimmon & Acetate buffer & Protein + polyphenols & $16.75 \mathrm{mg} / \mathrm{mL}$ & {$[38]$} \\
\hline Tomato fruit & 67\% Methanol (crude extract) & Polyphenols & $180.15 \mathrm{mg} / \mathrm{mL}$ & [39] \\
\hline Tomato fruit & $67 \%$ Methanol (purified extract) & Polyphenols & $5.83 \mathrm{mg} / \mathrm{mL}$ & {$[39]$} \\
\hline Hawthorn fruit & 95\% Ethanol & Polyphenols & $11.72 \mu \mathrm{g} / \mathrm{mL}$ & {$[40]$} \\
\hline Citrus limon peel & $50 \%$ Ethanol & Naringin & $81.91 \mu \mathrm{M}$ & {$[41]$} \\
\hline Piper spp. & Ether & Sesquiterpenes & $1.51 \mathrm{mg} / \mathrm{mL}$ & {$[44]$} \\
\hline Satureja thymbra & Hydrodistillation & Terpenes and terpenoids & $150.0 \mu \mathrm{g} / \mathrm{mL}$ & {$[45]$} \\
\hline Satureja thymbra & Methanol & Terpenes and terpenoids & $928.0 \mu \mathrm{g} / \mathrm{mL}$ & {$[45]$} \\
\hline Saffron & Methanol/water & Crocetin & $96.33 \mu \mathrm{M}$ & {$[46]$} \\
\hline Salvia officinalis & Ethyl acetate & Polyphenols & $30.00 \mu \mathrm{g} / \mathrm{mL}$ & [49] \\
\hline Cuminum cyminum & Water & $\mathrm{ND}$ & $0.437 \mu \mathrm{g} / \mathrm{mL}$ & [9] \\
\hline Salvia officinalis & Water & Polyphenols & $420.94 \mathrm{mg} / \mathrm{mL}$ & {$[50]$} \\
\hline Salvia officinalis & Water + fermentation & Polyphenols & $147.17 \mathrm{mg} / \mathrm{mL}$ & {$[50]$} \\
\hline Salvia officinalis & Methanol & Polyphenols & $24.04 \mathrm{mg} / \mathrm{mL}$ & {$[50]$} \\
\hline Salvia eriophora & Water & Polyphenols & $15.06 \mu \mathrm{g} / \mathrm{mL}$ & {$[51]$} \\
\hline Salvia eriophora & Methanol & Polyphenols & $9.91 \mu \mathrm{g} / \mathrm{mL}$ & [51] \\
\hline Ecklonia maxima & Ethyl acetate & Phloroglucinol & $579.32 \mu \mathrm{M}$ & {$[52]$} \\
\hline Ecklonia maxima & Ethyl acetate & Eckol & $76.70 \mu \mathrm{M}$ & {$[52]$} \\
\hline Ecklonia maxima & Ethyl acetate & Dibenzo dioxine tetraol & $84.48 \mu \mathrm{M}$ & {$[52]$} \\
\hline Ganoderma lucidum & Water & Polyphenols & $1.01 \mathrm{mg} / \mathrm{mL}$ & [53] \\
\hline Medicago sativa & $70 \%$ ethanol & Polyphenols & $31.13 \mu \mathrm{M}$ & [55] \\
\hline
\end{tabular}

${ }^{a}$ Where applicable, values are for the most active fractions or compounds. $\mathrm{IC}_{50}$, inhibitory concentration that reduced AChE activity by $50 \%$.

Table 2 Typical food sources of acetylcholinesterase (AChE) inhibitors and reported in vivo activities

\begin{tabular}{|c|c|c|c|c|c|c|}
\hline Sources & Extraction method & Active compound & Animal model & $\begin{array}{c}\text { Oral dose } \\
(\mathrm{mg} / \mathrm{kg} \mathrm{BW})\end{array}$ & In vivo effects & References \\
\hline Coilia mystus protein & Enzyme hydrolysis & Peptides & Mice & 333 & $\begin{array}{l}\text { Reduced escape latency } \\
\text { Increased number of crossings } \\
\text { Increased \% target time } \\
\text { Reduced number of errors }\end{array}$ & [18] \\
\hline$S$-allylcysteine & - & Amino acid & Rats & 150 & Reduced brain level of AChE & {$[20]$} \\
\hline Caffeine & - & Polyphenol & Rats & 50 & Inhibited brain $\mathrm{AChE}$ activity & [21] \\
\hline Prunella vulgaris & Ethyl acetate & Polyphenols & Rats & 100 & $\begin{array}{l}\text { Increased platform crossing } \\
\text { Increased time in target quadrant } \\
\text { Reduced brain level of AChE } \\
\text { Increased brain level of ACh }\end{array}$ & {$[24]$} \\
\hline Quinoa & Ethanol & Polyphenols & Mice & 100 & $\begin{array}{l}\text { Increased index of discrimination } \\
\text { Reduced crossing time } \\
\text { Reduced brain level of AChE }\end{array}$ & {$[27]$} \\
\hline Lutein & - & Lutein & Rats & 50 & $\begin{array}{l}\text { Reduced index of discrimination } \\
\text { Reduced brain level of AChE }\end{array}$ & {$[56]$} \\
\hline
\end{tabular}


the presence of several hydrophobic amino acids. Moreover, amino acid sequence of the F7 peptides showed predominance of tri- and tetrapeptides that also contained hydrophobic amino acids such as leucine, isoleucine, valine, alanine and tyrosine [15]. The small size of the hemp seed F7 peptides could enhance their ability to cross the $\mathrm{BBB}$ either by passive diffusion or peptide transporters and enter the brain where they could exert health benefits by suppressing excessive activity of AChE.

Another in vitro work examined the AChE-inhibitory activities of different hydrolysates obtained through enzymatic digestion of mannoproteins extracted from yeast [16]. The results also showed that AChE inhibition was dependent on type of enzyme used for proteolysis with proteinase- $\mathrm{K}$ and trypsin having the strongest activity at $54.4 \%$ and $42.6 \%$, respectively. When combinations of the enzymes were used, there was a general increase in the AChE-inhibitory activity of the resultant protein hydrolysates when compared to the hydrolysates from single enzyme hydrolysis. Therefore, the results suggest that greater proteolytic efficiency was achieved when the yeast proteins were hydrolyzed with a combination of two enzymes. In general, the pepsin/chymotrypsin combination produced a hydrolysate with strongest AChE inhibition at $59 \%$ compared to the maximum values of $39.3 \%$ and $32.1 \%$ for trypsin/chymotrypsin and proteinase K/chymotrypsin combinations, respectively [16]. Interestingly, the AChE-inhibitory activity of the yeast protein hydrolysates was not concentration-dependent, which suggests antagonistic effects of peptide activity or variations in solubility at different concentrations. In contrast, the AChEinhibitory activity of tuna liver enzymatic protein hydrolysates was concentration-dependent [17]. The differences indicate structural and solubility variations between the tuna and yeast peptides. Activity of the tuna liver peptides was also dependent on size with the biggest peptide fraction $(>10 \mathrm{kDa})$ having the strongest $\mathrm{AChE}$ inhibition. Therefore, it is possible that depending on the amino acid composition, the bigger tuna peptides bind to the AChE protein with greater intensity when compared to smaller peptides.

The only in vivo demonstration of the potential ameliorating effect of food protein hydrolysates against $\mathrm{AD}$ used a combination of alcalase, papain, and pancreatin to digest anchovy muscle proteins for 2, 4 and $8 \mathrm{~h}$ followed by feeding the anchovy protein hydrolysates (APH-2, APH-4 and APH-8, respectively) to scopolamineinduced amnesic mice [18]. Initial in vitro testing showed that $\mathrm{APH}-4$ and $\mathrm{APH}-8$ were the strongest $\mathrm{AChE}$ inhibitors with $\mathrm{IC}_{50}$ values of 152.10 and $159.76 \mathrm{mg} / \mathrm{g}$ protein, respectively when compared to $181.31 \mathrm{mg} / \mathrm{g}$ protein for the APH-2. From the mice feeding trial, inclusion of APHs [333 mg/kg Body Weight (BW)] in the diet led to upregulated escape latency during all the tests and was accompanied by down-regulated error times when compared to the control group that consumed regular feed (Table 2). Based on the animal to human dose conversion guide [19], this is equivalent to $27 \mathrm{mg} / \mathrm{kg} \mathrm{BW}$ of a human being. Therefore, a $70 \mathrm{~kg}$ person will need to ingest $1.9 \mathrm{~g}$ of the APH/day to obtain the reported health benefits. These improvements in escape latency error times confirm improved memory in mice that consumed the APHs. While the AChE activity in the mice brain was not measured, the reported results provide a proof of principle for the use of food protein-derived protein hydrolysates as therapeutic intervention agents during AD.

In addition to protein hydrolysates, other reports have suggested the use of proteins and amino acids as AChE inhibitors. For example, lysine was found to be the strongest AChE inhibitor among several other amino acids tested [18]. Arginine, cysteine, aspartic acid, alanine, valine, proline, serine and tyrosine were also found to active in decreasing order when tested at $10 \mathrm{mM}$. However, histidine, glutamic acid, methionine, leucine and tryptophan had no measurable AChE-inhibitory activity at $10 \mathrm{mM}$ test concentration. Kinetics evaluation showed that lysine inhibited AChE activity through a mixed mode, which indicate ability to bind to both the active and non-active sites of the enzyme. Combined with the effect of arginine, the results suggest that the presence of positively-charged amino acids could potentiate the AChE-inhibitory activity of food protein hydrolysates. This is consistent with the suggestion that the presence of arginine may have contributed to the potency of AChEinhibitory hemp seed protein hydrolysates. The effectiveness of positively-charged amino acids is believed to be due to the presence of an anionic area on the AChE protein where they bind and form a complex with an adjacent tryptophan residue to block substrate access to the active site [7]. Another in vivo work examined the effect of $S$-Allylcysteine (SAC), a garlic-derived sulfur-containing amino acid on the brain AChE activity in diabetic rats [20]. The diabetic rats were provided with daily $150 \mathrm{mg} / \mathrm{kg} \mathrm{BW}$ oral dose of SAC for 45 days (equivalent to $24.3 \mathrm{mg} / \mathrm{kg}$ BW human dose) followed by AChE activity determination in the brain cerebral cortex and hippocampus. The authors reported that the SAC treatment resulted in almost $40 \%$ reduction in brain AChE activity when compared to the control group. Therefore, apart from regular amino acids, derivatives such as SAC may also provide therapeutic benefits for the treatment or prevention of $\mathrm{AD}$.

\section{FOOD-DERIVED POLYPHENOLIC COMPOUNDS}

\subsection{Tea Extracts}

Polyphenols are considered the major secondary metabolites in plants and their consumption has been associated mostly with increased antioxidant effects but evidence also suggests their ability to act as enzyme inhibitors. Therefore, various works have examined the potential role of polyphenolic compounds in the prevention and treatment of $\mathrm{AD}$. Caffeine is an important component of tea and it has been shown that daily oral administration $(50 \mathrm{mg} / \mathrm{kg}$ BW) led to significant $\sim 16 \%$ decrease in rat brain AChE activity, an effect that was greater than that of caffeic acid [21]. An equal mixture of caffeine and caffeic produced better inhibition of rat brain AChE activity than caffeic acid alone but the effect was less than that observed for caffeine alone. Thus, increased caffeine consumption could be a means of attenuating the high levels of AChE activity associated with $\mathrm{AD}$. The demonstrated rat dose is equivalent to only $8.1 \mathrm{mg} / \mathrm{kg}$ BW for humans, which can be readily achieved through daily consumption of caffeinated drinks, especially coffee and tea products. In a recent report, the AChEinhibitory effect of cinnamoylated flavoalkaloids present in regular tea leaves (Camellia sinensis) was demonstrated [22]. These flavoalkaloids exhibited very strong $\mathrm{AChE}$ inhibition with $\mathrm{IC}_{50}$ values in the $0.13-1.04 \mu \mathrm{M}$ range, which suggest regular consumption of tea products could be beneficial towards AD management. A structurefunction analysis suggest that attachment of the pyrrilidinone ring to the $\mathrm{C} 6$ of the aromatic ring contributed to enhanced AChE 
inhibition when compared to attachment to C8. This is because the C6 position is close to two hydroxyl groups, which leads to enhanced electron density and ability to engage in ionic interactions with AChE amino acid residues. Another work also reported isolation of three AChE-inhibitory Hydroxycinnamoylated Catechins (HCCs) from Zijuan tea, a cultivar with purple buds, leaves and stem [23]. HCC 1, 2 and 3 had AChE-inhibitory $\mathrm{IC}_{50}$ values of 2.49, 11.41 and $62.26 \mu \mathrm{M}$, respectively when compared to the 0.09 for huperzine-A (standard compound). However, the HCCs are more potent than AChE-inhibitory drug galanthamine $\left(\mathrm{IC}_{50}=30 \mu \mathrm{M}\right)$, which suggests that these catechin derivatives may find use as modulators of AD symptoms. Qu et al. [24] have also reported on the memory improvement ability of Prunella vulgaris, a herb popularly used as tea in China. The herb was first mixed with water, the aqueous extract dried and further extracted stepwise with different solvents such as hexane, ethyl acetate and butanol. The extracts inhibited AChE activity to varying degrees but the ethyl acetate extract was the most effective with $\sim 62 \%$ inhibition at $224 \mu \mathrm{g} / \mathrm{mL}$ when compared to $<57 \%$ for the other extracts. Analysis of the ethyl acetate extract showed that the major identifiable polyphenolics in $P$. vulgaris were caffeic acid, rosmarinic acid, salviaflaside, benzaldehyde and protocatechuate. As shown in Table 2, oral administra-

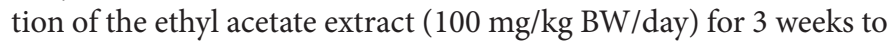
scopolamine-treated rats led to a significant decrease in AChE activity while ACh concentration increased to a level comparable to that of a drug (donezepil). Also important is the observation of attenuated neuronal cell death in the brain of rats that consumed the ethyl acetate extract, a positive outcome that was also similar to that of donezepil. Overall, treatment of the memory-impaired rats with the ethyl acetate extract of $P$. vulgaris led to decreased escape latency, as well as increased platform crossing and time in the target quadrant. These behavioural changes were directly related to the attenuation of brain AChE activity coupled with an upregulated level of ACh. In order to achieve similar health benefits in human beings, daily oral consumption of the $P$. vulgaris extract at $16 \mathrm{mg} / \mathrm{kg}$ BW dose will be required.

\subsection{Seed Extracts}

In an original research work, six dimers (called carthatins) consisting of a phenylpropanoid fused to a feruloylserotonin via a dihydrofuran ring were isolated form defatted safflower seed cake and tested for AChE-inhibitory activity [25]. Results showed that only carthatins $\mathrm{A}$ and $\mathrm{B}$ inhibited $\mathrm{AChE}$ activity with $\mathrm{IC}_{50}$ values of 17.96 and $66.83 \mu \mathrm{M}$, respectively, which indicate lower potency when compared to the $0.35 \mu \mathrm{M}$ for tacrine (positive control). Defatted rapeseed pomace was extracted with $95 \%$ ethanol and sinapine identified as the major phenolic compound in addition to the less abundant sinapic, caffeic, ferulic and synringic acids [26]. The rapeseed alcoholic extract at $0.25 \mathrm{mg} / \mathrm{mL}$ inhibited $85 \%$ of $\mathrm{AChE}$ activity, which is similar to the activity of sinapine. In contrast, the phenolic acids had only $25 \%$ inhibition of AChE activity, which indicate that sinapine is the main inhibitory compound in rapeseed pomace. A recent report provided information on the potential of an ethanolic red quinoa seed extract to ameliorate AD symptoms in scopolamine-induced memory deficient mice [27]. Oral administration of the quinoa seed extract $(100 \mathrm{mg} / \mathrm{kg}$ BW/day) to scopolamine-treated mice for 7 days resulted in increased discrimination index during the object recognition task when compared to mice given saline only. This is equivalent to $8.1 \mathrm{mg} / \mathrm{kg} \mathrm{BW}$ for an adult human being or a daily dose of $\sim 570 \mathrm{mg}$ for a $70 \mathrm{~kg}$ person. Using exploratory behaviour tests, mice that were administered the quinoa extract had reduced crossing and rearing times, which provided additional evidence of improved memory when compared to the control mice. Significant reductions in AChE activity within the brain cerebral cortex and hippocampus were also observed, which correlated with the observed improvements in the memory tests. Phytochemical analysis of the quinoa seed extract identified gentisic, $\alpha$-hydroxy isovaleric, hydroxybenzoic, $p$-coumaric, and dihydroxyphenyl propionic acids as well as hesperidin as the major phenolic compounds.

Hemp seed is now cultivated for the food and nutritional benefits, especially the high quality seed oil and proteins but also various minor components such as the polyphenolic compounds. After defatting hemp seed, the major lignanamides were then extracted with ethyl acetate followed by HPLC purification, structural elucidation and AChE-inhibitory activity testing [28]. All the 14 lignanamides attenuated the in vitro activity of AChE with 11.17-87.37\% inhibitory levels when tested at $100 \mu \mathrm{g} / \mathrm{mL}$. However, only compounds 7, 10, and $\mathbf{1 3}$ had sufficient inhibitory activities to enable determination of $\mathrm{IC}_{50}$ values of $216.0,46.2$ and $38.7 \mu \mathrm{M}$, respectively. Molecular docking studies showed that compounds 10 and 13 (most active) interacted differently with the AChE protein structure. For example, compound $\mathbf{1 0}$ occupied similar site as galanthamine while also interacting with peripheral anionic site on AChE in addition to the formation of hydrogen bonds and van der Waals interaction with other amino acid residues, especially tryptophan 84 and phenylalanine 330, respectively. In contrast, affinity of compound 13 to the AChE protein was stabilized mainly by hydrophobic interactions in addition to hydrogen bonds and van der Waals interactions.

In another work, the exudate of green gram (Vigna radiata L.) was prepared by soaking the seeds in water at $45^{\circ} \mathrm{C}$ overnight followed by filtration and lyophilisation of the liquid portion [29]. The work is based on the premise that during seed germination, nutrients are leached into the water, which can be collected and characterized for composition and bioactive activity. Analysis of the dried seed exudate showed the presence of mainly polyphenolic compounds and proteins, which were then isolated using ethanolic extraction and dialysis against water $(3.2 \mathrm{kDa}$ molecular weight cut-off membrane), respectively. The phenolic isolate consisted mainly of phenolic acids (gallic, ferulic, and sinapic acids) and flavonoids (vitexin and isovitexin) and exhibited a maximum of $\sim 90 \%$ inhibition of AChE in vitro activity at $25 \mu \mathrm{g}$ Gallic Acid Equivalent (GAE)/mL. The protein extract was separated into four fractions $(12,29,66$ and $150 \mathrm{kDa})$ using gel permeation chromatography and then tested for AChE-inhibitory activity. The total protein extract inhibited AChE activity with an $\mathrm{IC}_{50}$ value of $20.28 \mu \mathrm{g} / \mathrm{mL}$, which indicate lower potency when compared to 6.82 and $8.04 \mu \mathrm{g} / \mathrm{mL}$ for the 12 and $29 \mathrm{kDa}$ fractions, respectively. The 66 and $150 \mathrm{kDa}$ fractions were inactive, which explains the weaker AChE-inhibitory of the protein extract because their presence dilutes the strong inhibitory effect of the 12 and $29 \mathrm{kDa}$ proteins. The work illustrates the potential use of controlled germination to enhance bioactive properties of seeds. The lablab bean seed has also been studied for its potential to inhibit the in vitro activity of AChE. The lablab bean seeds were ground into flour and extracted with water, methanol/ water $(50 / 50)$ or absolute methanol. The results showed that the 
aqueous methanolic extract was the most potent with 3.06\% AChE inhibition when compared to $1.09 \%$ for the absolute methanol extract and $0 \%$ for the water extract [30]. Correlation analysis indicated 0.985 relationship between the AChE-inhibitory and total flavonoids of the aqueous methanolic extract while a similar but negative value was obtained for the total phenols. Therefore, the flavonoids were mainly responsible for the AChE-inhibitory effect of the lablab aqueous methanolic extract.

\subsection{Fruit Extracts}

The seedcase of mangosteen (Garcinia mangostana), a popular fruit in Southeast Asia was extracted with chloroform, ethanol and water followed by polyphenolic compounds identification and in vitro inhibitory testing against AChE [31]. The chloroform extract exhibited the strongest inhibition of human erythrocyte AChE with an $\mathrm{IC}_{50}$ value of $2.7 \mu \mathrm{g} / \mathrm{mL}$ when compared to $7.9,34.2$, and $0 \mu \mathrm{g} / \mathrm{mL}$ for ethanol, $30 \%$ ethanol and water extracts, respectively. Similar superior inhibitory value was also reported for activity of the chloroform extract against eel AChE $\left(\mathrm{IC}_{50}=4.8 \mu \mathrm{g} / \mathrm{mL}\right)$ when compared to $45.6 \mu \mathrm{g} / \mathrm{mL}$ for ethanol and zero for $30 \%$ ethanol and water. Therefore, the results suggest that highly hydrophobic molecules as present in the chloroform extract have stronger AChEinhibitory activity than the more hydrophilic compounds extracted by ethanol and water. However, UPLC fractionation of the chloroform extract generally resulted in reduced inhibitory potency of the obtained fractions $\left(\mathrm{IC}_{50}=5.2\right.$ to $>100 \mu \mathrm{g} / \mathrm{mL}$ for the human erythrocyte $\mathrm{AChE}$ and $\mathrm{IC}_{50}=2.5$ to $>100 \mu \mathrm{g} / \mathrm{mL}$ for the eel AChE). Only the UPLC peak 6 had a stronger inhibition against eel AChE with an $\mathrm{IC}_{50}$ value of $2.5 \mu \mathrm{g} / \mathrm{mL}$, which indicate that the inhibitory effectiveness of the chloroform extract was due to synergistic interactions between the polyphenolic components, which were identified as xanthonoids. A separate work also reported that the pooled fractions from preparative HPLC separation of bilberry fruit juice extract had in vitro AChE-inhibitory activity of $0.43 \mu \mathrm{M}$ eserine equivalent [32]. Further HPLC enrichment increased activity to $1.98 \mu \mathrm{M}$ eserine equivalent and identification of 14 polyphenolic compounds as the potential active compounds.

The flavonols present in Broussonetia papyrifera (paper mulberry) root have also been shown to exert inhibitory effect against AChE [33]. The water, 50\% ethanol, chloroform and absolute ethanol extracts of paper mulberry root had AChE-inhibitory $\mathrm{IC}_{50}$ values of $>200,25.3,22.7$ and $12.1 \mu \mathrm{M}$, respectively. Further purification of the absolute ethanol extract yielded six products with the prenylated flavonols 2, 3 and 4 being the most potent based on the AChE-inhibitory $\mathrm{IC}_{50}$ values of $0.8,3.1$, and $2.7 \mu \mathrm{M}$. A structureactivity analysis showed that compounds $2-4$ had 4 and 5 free hydroxyl groups when compared to the 2 and 3 free hydroxyl groups on compounds 5 and $\mathbf{6}$. Therefore, the evidence suggests that the presence of multiple free hydroxyl groups attached to the phenolic rings is an important structural feature that contributed to the strong AChE-inhibitory activity of the paper mulberry flavonols. Kinetics analysis indicated that compounds 2-4 are mixed inhibitors, which means they can bind to both the active and non-active sites of AChE. Compounds 2-4 were also shown to have very strong binding affinity with inhibition constants of $0.2-2.8 \mu \mathrm{M}$ and significant reductions in fluorescence intensity of AChE upon binding of the flavonols. A recent work has shown that an essential oil extracted from the fruit peel of Myrciaria floribunda inhibited in vitro activity of $\mathrm{AChE}$ with an $\mathrm{IC}_{50}$ value of $0.08 \mu \mathrm{g} / \mathrm{mL}$ [34]. Gas chromatography/mass spectroscopy analysis of the essential oil led to the identification of $\gamma$-cadinene, $\alpha$-muurolene, $\alpha$-selinene, $\gamma$-muurolene, $(E)$-caryophyllene, and $\delta$-cadinene as the major compounds. Molecular docking studies revealed $\delta$-cadinene and $\gamma$-cadinene having the lowest binding energy of -6.77 and -7.35 , respectively, which indicate stronger affinity for AChE than the other four compounds.

Grapes are popular fruits for the production of wine but the residual skins constitute a waste product that require increased valorization. The methanolic extract of grape skin was shown to consist mainly of four anthocyanins, malvidin 3-O-glucoside, petunidin 3-O-glucoside, delphinidin 3-O-glucoside and cyanidin 3-O-rutinoside [35]. The grape seed skin extract was an effective inhibitor of in vitro AChE activity with an $\mathrm{IC}_{50}$ value of 363.61 $\mu \mathrm{g} / \mathrm{mL}$. Bananas (Musa acuminate) are also very popular with significant uses of the leaves and fruits for food and medicinal purposes. Solvent extraction of the banana leaf and fruit identified the ethyl acetate fraction as the most active AChE inhibitor with $\mathrm{IC}_{50}$ values of 404.4 and $478.2 \mu \mathrm{g} / \mathrm{mL}$, respectively [36]. This may be due to differences in the level of phytochemicals as it was reported that the total phenolic contents of leaves and fruit were 85.4-911.9 and 12.0-70.2 mg GAE/g, respectively. Overall, the polar fractions were stronger AChE inhibitors than the non-polar fractions with kaempferil-3-O-rutinoside and quercetin-3-O-rutinoside as the dominant compounds in the ethyl acetate fraction. In a previous work, the methanolic extracts $(100 \mu \mathrm{g} / \mathrm{mL})$ of banana fruit pulp and leaf were also shown to inhibit the in vitro activity of AChE at values ranging from 50 to $58 \%$ and $\sim 70 \%$, respectively [37]. The stronger AChE-inhibitory effect of the banana leaf was also attributed to higher levels of polyphenolic compounds and especially flavonoids. Thus, the two reports confirmed that the stronger AChE-inhibitory activity of banana leaf was due to the higher contents of polyphenolic compounds when compared to the fruit. The plum is another popular fruit whose anti-AChE activity has been examined and the aqueous extract reported to be effective with an $\mathrm{IC}_{50}$ value of $16.75 \mathrm{mg} / \mathrm{mL}$ [38]. However, this activity is very low when compared to the $\mathrm{IC}_{50}$ values of solvent extracts of other fruits, which have been shown to be $<1 \mathrm{mg} / \mathrm{mL}$. The weak activity of the plum extract could be due to the use of water for extraction, which may have been less effective in solubilizing a wide variety of polyphenolic compounds when compared to the solvents (ethyl acetate, ethanol, butanol, etc.) that were used in other works.

Tomatoes are important sources of nutrients in the human diet but they could also provide active bioactive compounds that can attenuate AChE activity as evident from a recent work [39]. AChEinhibitory activity depended on the tomato variety with an $\mathrm{IC}_{50}$ value range of $5.83-200.65 \mathrm{mg} / \mathrm{mL}$ for the methanolic extracts when compared to the $0.83-23.14 \mu \mathrm{g} / \mathrm{mL}$ for standard phenolic compounds such as caffeic acid, chlorogenic acid, hesperidin, rutin, quercetin and naringenin. Interestingly, most of the standard phenolic compounds were found to be present in the tomato methanolic extract, which suggest that the low activity may be due to antagonistic or dilution effect of other phenolic compounds present in the extract. Correlation analysis revealed a strong positive relationship of chlorogenic acid, caffeic acid, caffeoyl-glucose, linocaffein, vanillic acid, rutin, saluenin, and $p$-coumaric acid with anti-AChE activity of the tomato extracts [39]. In a previous work, the Hawthorn Fruit (HF) peel was extracted with 95\% ethanol (PHF) followed by further separation on a macroporous 
resin column to obtain a $20 \%$ ethanol eluate (EPHF), both of which were tested as potential AChE inhibitors [40]. The $\mathrm{IC}_{50}$ values were $1385,616.40$ and $11.72 \mu \mathrm{g} / \mathrm{mL}$ for HF, PHF and EPHF, respectively, which indicate the effectiveness of ethanolic extraction and column fractionation in obtaining a product highly enriched with potent AChE inhibitors. This was evident in the amount of the identified compounds (ideain, cyanidin 3-arabinoside, hyperoside, isoquercitin, epicatechin, and chlorogenic acid), which totalled $23.23 \%$ for EPHF and $0.088 \%$ for PHF. A recent work also identified AChEinhibitory phenolic compounds present in lemon fruit peel. The compounds were neoeriocitrin, isonaringin, naringin, heperidin, neohesperidin, limonin and poncirin with AChE-inhibitory $\mathrm{IC}_{50}$ values of $80.97,116.45,81.91,134.44,84.69$, and $178.13 \mu \mathrm{M}$, respectively [41]. In PC12 cells that were treated with the Amyloidbeta $(\mathrm{A} \beta)$ peptide, addition of each identified phenolic compound led to concentration-dependent reduction in cell death. Therefore, in addition to inhibiting AChE, the lemon peel phenolic compounds attenuated cellular injury caused by the $\mathrm{A} \beta$ peptide, which has significance in the treatment of AD. This is because it is known that $\mathrm{AChE}$ activity is enhanced in the presence of $\mathrm{A} \beta$ peptide and this leads to high levels of the AChE- $\mathrm{A} \beta$ complex, which is more toxic than $\mathrm{A} \beta$ aggregates and can cause severe deterioration of brain functions $[42,43]$. Therefore, the ability of lemon phenolic compounds to simultaneously inhibit AChE activity and reduce $\mathrm{A} \beta$ peptide toxicity suggests an important mechanism to break the vicious cycle of events that worsen $\mathrm{AD}$ symptoms.

\subsection{Extracts of Spices}

In general, spices are critical ingredients in traditional cooking all over the world but also serve as important ingredients for the formulation of various food products. The Piper nigrum fruit (peppers) is undoubtedly one of the most used spices throughout the world. The essential oil of leaves and stems of $P$. nigrum varieties were extracted and tested against AChE activity with results showing a wide range (89-147\%) of inhibitory values [44]. Asaricin was identified as the main active compound with an $\mathrm{IC}_{50}$ value of 0.44 $\mathrm{mg} / \mathrm{mL}$. Satureja thymbra (savoury) is another important spice that has been studied for the anti-AChE activity of its essential oil. Using hydrodistillation, the essential oil of $S$. thymbra inhibited AChE activity with an $\mathrm{IC}_{50}$ value of $150 \mu \mathrm{g} / \mathrm{mL}$, which shows stronger potency than the methanolic extract that had a value of $928 \mu \mathrm{g} / \mathrm{mL}$ [45]. The major components of the essential oil was elucidated with gas chromatography-mass spectroscopy and found to be $p$-cymene, $\gamma$-terpinene, thymol, and carvacrol with AChE-inhibitory $\mathrm{IC}_{50}$ values of $>1000,181,47.5$, and $182 \mu \mathrm{g} / \mathrm{mL}$, respectively. Since $S$. thymbra is very rich in thymol and carvacrol, regular consumption of this spice may provide therapeutic relief from the damaging symptoms associated with AD. Saffron components have also been demonstrated as strong AChE inhibitors with $\mathrm{IC}_{50}$ values of $21.09,96.33$ and $107.1 \mu \mathrm{M}$ for safranal, crocetin and dimethylcrocetin, respectively [46]. Thus, methylation resulted in decreased activity of crocetin, probably due to increased steric hindrance caused by the two methyl groups, which reduced interactions of dimethylcrocetin with AChE. Kinetics analysis revealed that the three saffron compounds inhibited AChE activity through a mixed mode with molecular docking confirming binding to the active site as well as the non-active site peripheral anionic residues of the enzyme. Sage (Salvia officinalis) is another well-established culinary spice that has been examined for potential AChE activity inhibition. In an earlier work, the single dose (300 or $600 \mathrm{mg}$ ) of a sage extract was reported to enhance cognitive performance and mood in healthy human volunteers through attenuation of AChE activity [47]. Another report suggested that an undefined sage extract could be used to manage mild cognitive impairment and reduce agitation in patients [48]. Using a series of initial sequential chloroform and methanol extractions, a final ethyl acetate extract was obtained with up to $55 \%$ AChE inhibition at $40 \mu \mathrm{g} / \mathrm{mL}$ [49]. This ethyl acetate extract consisted mainly of abietane terpenes (49.7\%) and hydroxycinnamoyl derivatives (39.63\%). Rosmarinic acid, a well-known AChE inhibitor was the dominant (83.42\%) hydroxycinnamoyl derivative. The cumin seed is highly valued not only for the aroma but also the potential therapeutic properties. Aqueous extraction of the cumin seed afforded an extract with up to $70 \% \mathrm{AChE}$ inhibition at $50 \mu \mathrm{g} / \mathrm{mL}$ test concentration [9]. Kinetics of enzyme inhibition revealed a competitive mode at low concentrations $(12.5$ and $25 \mu \mathrm{g} / \mathrm{mL}$ ) but a mixed-type at higher concentrations (50 and $100 \mu \mathrm{g} / \mathrm{mL}$ ). Thus the compounds present in the cumin seed extract could bind to AChE active and nonactive sites to cause reductions in rate of enzyme catalysis. In a recent report, sage extracts were prepared using different methods such as fermentation, Soxhlet extraction and sonication in combination with aqueous and methanol extractions [50]. The reported data showed that Soxhlet extraction and sonic extraction with methanol produced the most active AChE-inhibitory extracts with $\mathrm{IC}_{50}$ values of 24.04 and $31.45 \mathrm{mg} / \mathrm{mL}$, respectively. In contrast, the aqueous extract was the least active with an $\mathrm{IC}_{50}$ value of 420.94 $\mathrm{mg} / \mathrm{mL}$, which suggest that solvent extraction was more efficient in solubilizing the AChE-inhibitory compounds when compared to water extraction. This was reflected in the total polyphenolic content, which was lowest for the aqueous extract (4.53 $\mathrm{mg} \mathrm{GAE} / \mathrm{g}$ ) when compared to the Soxhlet extract (64.51 mg GAE/g). A related plant called Salvia eriophora has also been investigated for potential use as a source of AChE-inhibitory compounds [51]. The aqueous and methanol extracts of S. eriophora were shown to contain a wide variety of compounds but gallic acid, epicatechin, chlorogenic acid, salvigenin, fumaric acid and ferulic acid were commonly present. The aqueous and methanolic extracts had $\mathrm{IC}_{50}$ values of 15.06 and $9.91 \mu \mathrm{g} / \mathrm{mL}$, respectively, which suggest that the latter contains compounds with stronger affinity for AChE.

\subsection{Miscellaneous Extracts}

Macroalgae are consumed in several parts of the world not only for the nutrient supply but the ability to provide medicinal benefits. The brown alga, Ecklonia maxima was subjected to various solvent extractions, which were tested for AChE-inhibitory activity [52]. The methanol, hexane, dichloromethane, ethyl acetate and butanol extracts had $\mathrm{IC}_{50}$ values of $381.50,97.82,117.50,62.61$ and 150.80 $\mu \mathrm{g} / \mathrm{mL}$, respectively. The most active fraction (ethyl acetate) was subsequently purified by gel permeation chromatography to obtain three compounds, namely Eckol, dibenzo(1,4) dioxine-2,4,7,9tetraol and phloroglucinol with $\mathrm{IC}_{50}$ values of $76.70,84.48$ and $579.32 \mu \mathrm{M}$, respectively. The higher AChE-inhibitory activity of eckol may be due to the presence of six hydroxyl groups in addition to three aromatic rings, which provide the molecule with several electronic interaction features, hence stronger affinity for the enzyme protein. In contrast, dibenzo $(1,4)$ dioxine-2,4,7,9-tetraol 
and phloroglucinol have two and one aromatic rings in addition to three and four hydroxyl groups, respectively. This theory is supported by the higher AChE-inhibitory activity of dibenzo(1,4) dioxine-2,4,7,9-tetraol when compared to phloroglucinol.

Ganoderma lucidum, a valuable edible fungus (mushroom) was grown on germinated rice, dried, ground into a powder and then extracted with water [53]. HPLC analysis of the aqueous extract indicated the presence of 13 polyphenolic compounds with quercetin, ursolic acid, kaempferol, terpeniol, coumarin, catechism, myricetin and ferulic acid being dominant. The aqueous extract exhibited concentration-dependent inhibition of AChE activity with an $\mathrm{IC}_{50}$ value of $1.01 \mathrm{mg} / \mathrm{mL}$. Correlation analysis showed a positive relationship of the AChE-inhibitory activity with the levels of total phenolic $\left(r^{2}=0.7736\right)$ and flavonoids $\left(r^{2}=0.7755\right)$. In a recent work, three edible vegetable leaves (Solanum macrocarpon, Amaranthus viridis, and Telfairia occidentalis) were also extracted with water followed by determination of AChE-inhibitory properties [54]. Four main polyphenolic compounds, myricetin, gallic acid, caffeic acid and rutin were identified to be present in the three leaf extracts. The T. occidentalis extract was shown to be the most active with up to $20 \% \mathrm{AChE}$ activity inhibition at $20 \mu \mathrm{g} / \mathrm{mL}$ test concentration while $A$. viridis extract was the least active. In this work, the type, level and time of fertilizer application were shown to influence the AChE-inhibitory potency of the leaf extracts, which suggest an agronomic route towards enhancing bioactivity. Another vegetable that has been investigated for AChE-inhibitory activity is the Medicago sativa plant, which is commonly consumed as part of soups, salads, tortillas, etc. [55]. Phytochemical analysis of $M$. sativa stem resulted in the identification of 11 polyphenolic compounds. Compounds 1, 2, and 3 had the strongest AChEinhibitory effect with $\mathrm{IC}_{50}$ values of $31.13,43.32$ and $33.40 \mu \mathrm{g} / \mathrm{mL}$, respectively. Compounds 7, 8 and $\mathbf{9}$ had very weak AChE-inhibitory activity with $\mathrm{IC}_{50}$ values $>100 \mu \mathrm{g} / \mathrm{mL}$. Molecular docking studies suggest that the strong activities of compounds $\mathbf{1}$ and $\mathbf{3}$ were due to better bonding to AChE (lowest moldock scores of -163.87 and -161.77 , respectively). Compounds 1 and 3 also formed hydrogen and hydrophobic bonds with the amide residues of critical AChE protein residues such as His 447 and Glu 202.

Lutein is a carotenoid that is well-known for its antioxidant properties but a recent work also showed potential to improve ethanolinduced memory impairment in rats [56]. Wistar rats that were given ethanol had significantly higher AChE activity in the cerebral cortex and hippocampus, which was accompanied by decreased discrimination index. However, daily oral administration of lutein using $50 \mathrm{mg} / \mathrm{kg} \mathrm{BW}$ ( $8.1 \mathrm{mg} / \mathrm{kg}$ BW human dose equivalent) for 14 days led to blunting of the ethanol-induced increase in $\mathrm{AChE}$ activity in both the cerebral cortex and hippocampus along with increased discrimination index. Thus, in addition to the powerful free radical scavenging activity, lutein could also be used as a neuroprotective therapeutic agent because of the ability to modulate AChE activity in the brain.

\section{CONCLUSION}

Foods remain veritable sources of bioactive compounds with potential use as neuroprotective agents. Current knowledge has established that various aqueous or organic solvent extracts of foods contain phenolic compounds that can interact with and block
AChE activity both during in vitro and in vivo tests. Interestingly, for some of these extracts, attenuated brain levels of AChE activity were correlated with improved memory and behaviour in animal and human tests. One of the key outcomes of these experiments is that the presence of multiple hydroxyl groups as well as aromatic rings potentiate the AChE-inhibitory activity of phenolic compounds. However, in addition to the mostly polyphenolic compounds present in food extracts, in situ production of AChEinhibitory peptides through enzymatic hydrolysis of food proteins have also been successfully demonstrated. While attenuated rat brain levels of AChE have been shown to accompany ingestion of peptides, additional information is required on the structural features that contribute to enhanced potency of peptides against AChE. Therefore, future work is required to elucidate the relationships of specific amino acids and their sequence on a peptide chain with AChE-inhibitory potency at the in vitro and in vivo levels. Toxicological studies are also needed to determine the metabolic fate of phytochemicals and peptides in the brain with a view to ensuring safety while maintaining efficacy as neuroprotective agents.

\section{CONFLICTS OF INTEREST}

The author declares no conflicts of interest.

\section{ACKNOWLEDGMENT}

The author acknowledges support from the Natural Sciences and Engineering Council of Canada (NSERC), funding reference number RGPIN 2018-06019. Cette recherche a été financée par le Conseil de recherches en sciences naturelles et en génie du Canada (CRSNG), numéro de référence RGPIN 2018-06019.

\section{REFERENCES}

[1] Li Y, Zhang XX, Jiang LJ, Yuan L, Cao TT, Li X, et al. Inhibition of acetylcholinesterase (AChE): a potential therapeutic target to treat Alzheimer's disease. Chem Biol Drug Des 2015;86:776-82.

[2] Otaegui-Arrazola A, Amiano P, Elbusto A, Urdaneta E, MartínezLage P. Diet, cognition, and Alzheimer's disease: food for thought. Eur J Nutr 2014;53:1-23.

[3] Malomo SA, Aluko RE. In vitro acetylcholinesterase-inhibitory properties of enzymatic hemp seed protein hydrolysates. J Am Oil Chem Soc 2016;93:411-20.

[4] Singh M, Kaur M, Kukreja H, Chugh R, Silakari O, Singh D. Acetylcholinesterase inhibitors as Alzheimer therapy: from nerve toxins to neuroprotection. Eur J Med Chem 2013;70:165-88.

[5] Silman I, Sussman JL. Acetylcholinesterase: 'classical' and 'nonclassical' functions and pharmacology. Curr Opin Pharmacol 2005; 5:293-302.

[6] Ghribia L, Ghouilaa H, Omrib A, Besbesb M, Janneta HB. Antioxidant and anti-acetylcholinesterase activities of extracts and secondary metabolites from Acacia cyanophylla. Asian Pac J Trop Biomed 2014;4:S417-S23.

[7] Saravanaraman P, Chinnadurai RK, Boopathy R. A new role for the nonpathogenic nonsynonymous single-nucleotide polymorphisms of acetylcholinesterase in the treatment of Alzheimer's disease: a computational study. J Comput Biol 2014;21:632-47. 
[8] Iannello C, Pigni NB, Antognoni F, Poli F, Maxia A, de Andrade JP, Bastida J. A potent acetylcholinesterase inhibitor from Pancratium illyricum L. Fitoterapia 2014;92:163-7.

[9] Kumar S, Chowdhury S. Kinetics of acetylcholinesterase inhibition by an aqueous extract of Cuminum cyminum seeds. Int J Appl Sci Biotechnol 2014;2:64-8.

[10] Montagne A, Barnes SR, Sweeney MD, Halliday MR, Sagare AP, Zhao Z, et al. Blood-brain barrier breakdown in the aging human hippocampus. Neuron 2015;85:296-302.

[11] Ishida Y, Shibata Y, Fukuhara I, Yano Y, Takehara I, Kaneko K. Effect of an excess intake of casein hydrolysate containing ValPro-Pro and Ile-Pro-Pro in subjects with normal blood pressure, high-normal blood pressure, or mild hypertension. Biosci Biotechnol Biochem 2011;75:427-33.

[12] Yuda N, Tanaka M, Tokushima M, Abe F. Safety evaluation of high-dose intake of casein-derived peptide Met-Lys-Pro in healthy adults: a randomized, double-blind, placebo-controlled trial. Food Sci Nutr 2021;9:662-71.

[13] Banks WA. Peptides and the blood-brain barrier. Peptides 2015; 72:16-19.

[14] Zare-Zardini H, Tolueinia B, Hashemi A, Ebrahimi L, Fesahat F. Antioxidant and cholinesterase inhibitory activity of a new peptide from Ziziphus jujuba fruits. Am J Alzheimers Dis Other Demen 2013;28:702-9.

[15] Malomo SA, Aluko RE. Kinetics of acetylcholinesterase inhibition by hemp seed protein-derived peptides. J Food Biochem 2019;43:e12897.

[16] Spontón PG, Spinelli R, Drago SR, Tonarelli GG, Simonetta AC. Acetylcholinesterase-inhibitor hydrolysates obtained from 'in vitro' enzymatic hydrolysis of mannoproteins extracted from different strains of yeasts. Int J Food Sci Technol 2016;51:300-8.

[17] Ahn CB, Lee KH, Je JY. Enzymatic production of bioactive protein hydrolysates from tuna liver: effects of enzymes and molecular weight on bioactivity. Int J Food Sci Technol 2010;45:562-8.

[18] Zhao T, Xu J, Zhao H, Jiang W, Guo X, Zhao M, et al. Antioxidant and anti-acetylcholinesterase activities of anchovy (Coilia mystus) protein hydrolysates and their memory-improving effects on scopolamine-induced amnesia mice. Int J Food Sci Technol 2017; 52:504-10

[19] Reagan-Shaw S, Nihal M, Ahmad N. Dose translation from animal to human studies revisited. FASEB J 2008;22:659-61.

[20] Saravanan G, Ponmurugan P. Attenuation of streptozotocininduced alterations in acetylcholinesterase and antioxidant system by $S$-allycysteine in rats. Food Biosci 2013;4:31-7.

[21] Akomolafe SF. The effects of caffeine, caffeic acid, and their combination on acetylcholinesterase, adenosine deaminase and arginase activities linked with brain function. J Food Biochem 2017;41:e12401.

[22] Gaur R, Ke JP, Zhang P, Yang Z, Bao GH. Novel cinnamoylated flavoalkaloids identified in tea with acetylcholinesterase inhibition effect. J Agric Food Chem 2020;68:3140-8.

[23] Wang W, Fu XW, Dai XL, Hua F, Chu GX, Chu MJ, et al. Novel acetylcholinesterase inhibitors from Zijuan tea and biosynthetic pathway of caffeoylated catechin in tea plant. Food Chem 2017;237:1172-8.

[24] Qu Z, Zhang J, Yang H, Gao J, Chen H, Liu C, et al. Prunella vulgaris L., an edible and medicinal plant, attenuates scopolamineinduced memory impairment in rats. J Agric Food Chem 2017;65:291-300.
[25] Peng XR, Wang X, Dong JR, Qin XJ, Li ZR, Yang H, et al. Rare hybrid dimers with anti-acetylcholinesterase activities from a safflower (Carthamus tinctorius L.) seed oil cake. J Agric Food Chem 2017;65:9453-9.

[26] Yates K, Pohl F, Busch M, Mozer A, Watters L, Shiryaev A, et al. Determination of sinapine in rapeseed pomace extract: its antioxidant and acetylcholinesterase inhibition properties. Food Chem 2019;276:768-75.

[27] Souza SP, Roos AA, Gindri AL, Domingues VO, Ascari J, Guerra GP. Neuroprotective effect of red quinoa seeds extract on scopolamine-induced declarative memory deficits in mice: the role of acetylcholinesterase and oxidative stress. J Funct Foods 2020;69:103958.

[28] Yan X, Tang J, dos Santos Passos C, Nurisso A, Simões-Pires CA, Ji M, et al. Characterization of lignanamides from hemp (Cannabis sativa L.) seed and their antioxidant and acetylcholinesterase inhibitory activities. J Agric Food Chem 2015;63:10611-19.

[29] Basha SA, Maheswaraiah A, Prasada Rao UJS. Antioxidant profile, acetylcholinesterase inhibition, and platelet aggregation of polyphenols and proteins from germinating green gram (Vigna radiata). Int J Food Prop 2017;20:S959-S71.

[30] Habib HM, Theuri SW, Kheadr E, Mohamed FE. DNA and BSA damage inhibitory activities, and anti-acetylcholinesterase, antiporcine $\alpha$-amylase and antioxidant properties of Dolichos lablab beans. Food Funct 2017;8:881-7.

[31] Ryu HW, Oh SR, Curtis-Long MJ, Lee JH, Song HH, Park KH. Rapid identification of cholinesterase inhibitors from the seedcases of mangosteen using an enzyme affinity assay. J Agric Food Chem 2014;62:1338-43.

[32] Borowiec K, Szwajgier D, Targoński Z, Demchuk OM, Cybulska J, Czernecki T, et al. Cholinesterase inhibitors isolated from bilberry fruit. J Funct Foods 2014;11:313-21.

[33] Ryu HW, Curtis-Long MJ, Jung S, Jeong IY, Kim DS, Kang KY, et al. Anticholinesterase potential of flavonols from paper mulberry (Broussonetia papyrifera) and their kinetic studies. Food Chem 2012;132:1244-50.

[34] da Silva Barbosa DC, Holanda VN, de Assis CRD, de Oliveira Farias de Aguiar JCR, doNascimento PH, da Silva WV, et al. Chemical composition and acetylcholinesterase inhibitory potential, in silico, of Myrciaria floribunda (H. West ex Willd.) O. Berg fruit peel essential oil. Ind Crops Prod 2020;151:112372.

[35] Pervin M, Hasnat MA, Lee YM, Kim DH, Jo JE, Lim BO. Antioxidant activity and acetylcholinesterase inhibition of grape skin anthocyanin (GSA). Molecules 2014;19:9403-18.

[36] Oresanya IO, Sonibare MA, Gueye B, Balogun FO, Adebayo S, Ashafa AOT, et al. Isolation of flavonoids from Musa acuminata Colla (Simili radjah, ABB) and the in vitro inhibitory effects of its leaf and fruit fractions on free radicals, acetylcholinesterase, 15-lipoxygenase, and carbohydrate hydrolyzing enzymes. J Food Biochem 2020;44:e13137.

[37] Ayoola IO, Gueye B, Sonibare MA, Abberton MT. Antioxidant activity and acetylcholinesterase inhibition of field and in vitro grown Musa L. species. J Food Measure Charact 2017;11:488-99.

[38] Faiz O, Baltas N. Polyphenol oxidase properties, anti-urease, and anti-acetylcholinesterase activity of Diospyros lotus L. (Plum persimmon). Int J Food Prop 2017;20:1186-96.

[39] Błaszczak W, Jeż M, Szwengiel A. Polyphenols and inhibitory effects of crude and purified extracts from tomato varieties on the formation of advanced glycation end products and the activity of 
angiotensin-converting and acetylcholinesterase enzymes. Food Chem 2020;314:126181.

[40] Wu P, Li F, Zhang J, Yang B, Ji Z, Chen W. Phytochemical compositions of extract from peel of hawthorn fruit, and its antioxidant capacity, cell growth inhibition, and acetylcholinesterase inhibitory activity. BMC Complement Altern Med 2017;17:151.

[41] Liu C, Hou W, Li S, Tsao R. Extraction and isolation of acetylcholinesterase inhibitors from Citrus limon peel using an in vitro method. J Sep Sci 2020;43:1531-43.

[42] Melo JB, Agostinho P, Oliveira CR. Involvement of oxidative stress in the enhancement of acetylcholinesterase activity induced by amyloid beta-peptide. Neurosci Res 2003;45:117-27.

[43] Bartolini M, Bertucci C, Cavrini V, Andrisano V. $\beta$-Amyloid aggregation induced by human acetylcholinesterase: inhibition studies. Biochem Pharmacol 2003;65:407-16.

[44] Xiang CP, Han JX, Li XC, Li YH, Zhang Y, Chen L, et al. Chemical composition and acetylcholinesterase inhibitory activity of essential oils from Piper species. J Agric Food Chem 2017;65:3702-10.

[45] Öztürk M. Anticholinesterase and antioxidant activities of Savoury (Satureja thymbra L.) with identified major terpenes of the essential oil. Food Chem 2012;134:48-54.

[46] Geromichalos GD, Lamari FN, Papandreou MA, Trafalis DT, Margarity M, Papageorgiou A, et al. Saffron as a source of novel acetylcholinesterase inhibitors: molecular docking and in vitro enzymatic studies. J Agric Food Chem 2012;60:6131-8.

[47] Kennedy DO, Pace S, Haskell C, Okello EJ, Milne A, Scholey AB. Effects of cholinesterase inhibiting sage (Salvia officinalis) on mood, anxiety and performance on a psychological stressor battery. Neuropsychopharmacol 2006;31:845-52.

[48] Akhondzadeh S, Noroozian M, Mohammadi M, Ohadinia S, Jamshidi AH, Khani M. Salvia officinalis extract in the treatment of patients with mild to moderate Alzheimer's disease: a double blind, randomized and placebo-controlled trial. J Clin Pharm Ther 2003;28:53-9.
[49] Pacifico S, Piccolella S, Lettieri A, Nocera P, Bollino F, Catauro M. A metabolic profiling approach to an Italian sage leaf extract (SoA541) defines its antioxidant and anti-acetylcholinesterase properties. J Funct Foods 2017;29:1-9.

[50] Sharma Y, Fagan J, Schaefer J. In vitro screening for acetylcholinesterase inhibition and antioxidant potential in different extracts of sage (Salvia officinalis L.) and rosemary (Rosmarinus officinalis L.). J Biol Act Prod Nat 2020;10:59-69.

[51] Bursal E, Aras A, Kılıç Ö, Taslimi P, Gören AC, Gülçin İ. Phytochemical content, antioxidant activity, and enzyme inhibition effect of Salvia eriophora Boiss. \& Kotschy against acetylcholinesterase, $\alpha$-amylase, butyrylcholinesterase, and $\alpha$-glycosidase enzymes. J Food Biochem 2019;43:e12776.

[52] Kannan RRR, Aderogba MA, Ndhlala AR, Stirk WA, Van Staden J. Acetylcholinesterase inhibitory activity of phlorotannins isolated from the brown alga, Ecklonia maxima (Osbeck) Papenfuss. Food Res Int 2013;54:1250-4.

[53] Hasnat MA, Pervin M, Lim BO. Acetylcholinesterase inhibition and in vitro and in vivo antioxidant activities of Ganoderma lucidum grown on germinated brown rice. Molecules 2013;18: 6663-78.

[54] Olarewaju OA, Alashi AM, Taiwo KA, Oyedele D, Adebooye OC, Aluko RE. Influence of nitrogen fertilizer micro-dosing on phenolic content, antioxidant, and anticholinesterase properties of aqueous extracts of three tropical leafy vegetables. J Food Biochem 2018;42:e12566.

[55] Liu XG, Huang MY, Gao PY, Liu CF, Sun YQ, Lv MC, et al Bioactive constituents from Medicago sativa L. with antioxidant, neuroprotective and acetylcholinesterase inhibitory activities. J Funct Foods 2018;45:371-80.

[56] Geiss JMT, Sagae SC, Paz EDR, de Freitas ML, Souto NS, Furian AF, et al. Oral administration of lutein attenuates ethanol-induced memory deficit in rats by restoration of acetylcholinesterase activity. Physiol Behav 2019;204:121-8. 